\title{
ENTRE A BASE NACIONAL COMUM CURRICULAR E A AVALIAÇÃO: A SUBSTITUIÇÃO TECNOLÓGICA NO ENSINO FUNDAMENTAL
}

\author{
Raquel Goulart Barreto ${ }^{1}$
}

\begin{abstract}
RESUMO: Este artigo visa a analisar o desenho de uma nova regulaçáo para o ensino fundamental, com base nas relaçóes entre o par currículo centralizado e avaliação externa unificada. Está estruturado em quatro seçóes. A primeira introduz a temática por meio do diálogo com autores de diferentes filiaçóes teóricas. A segunda discute a configuração atual das políticas, bem como as condiçôes de possibilidade de expropriação do trabalho docente. A terceira propóe a noção de substituição tecnológica como elo entre competências e avaliação, concentrando-se no caso da Secretaria Municipal de Educação do Rio de Janeiro. Finalmente, a quarta seção empreende a análise crítica dos discursos de professores, de modo a dimensionar os sentidos em disputa por hegemonia.
\end{abstract}

Palavras-chave: Política educacional. Currículo. Avaliação. Ensino. Substituição tecnológica.

\section{BETWEEN THE COMMON CORE NATIONAL CURRICULUM AND TESTING: ON TECNOLOGICAL SUBSTITUTION IN ELEMENTARY SCHOOLS}

ABSTRACT: This paper aims at analysing the design of a new regulation for the elementary school, on the basis of the relationship between the pair centralized curriculum and unified testing. It is structured in four sections. The first one introduces the theme by means of dialogue with authors of different theoretical affiliations. The second discusses the configuration of current policies, as well as the conditions of possibility to expropriate the teaching work. The third proposes the notion of technological substitution as a link between competencies and assessment, focusing on the case of the Municipal Secretariat of Education of Rio de Janeiro, Brazil. Finally, the fourth section undertakes a critical analysis of teachers' discourses, so as to grasp the senses in hegemonic struggle.

Keywords: Educational policies. Curriculum. Evaluation. Teaching. Technological substitution.

\footnotetext{
*Artigo resultado do projeto de pesquisa "Dimensôes da Substituiçáo Tecnológica nas Políticas Educacionais: o Caso da Secretaria Municipal do Rio de Janeiro", financiado pelo Conselho Nacional de Desenvolvimento Científico e Tecnológico $(\mathrm{CNPq})$ e pela Fundaçáo de Apoio à Pesquisa do Estado do Rio de Janeiro (FAPERJ).

${ }^{1}$ Universidade do Estado do Rio de Janeiro (UERJ) - Rio de Janeiro (RJ), Brasil. E-mail: raquel@uol.com.br DOI: 10.1590/ES0101-73302016159933
} 


\section{ENTRE LA BASE NATIONALE COMMUN CURRICULAIRE ET L'ÉVALUATION: LA SUBSTITUTION TECHNOLOGIQUE À L'ÉDUCATION E BASE}

RESUMÉ: Cet article vise à analyser la conception d'un nouveau règlement pour l'éducation au collège, basé sur la relation entre la paire: curriculum centralisé et l'évaluation externe unifiée. Il est structuré en quatre sections. La première présente le problème par le dialogue avec les auteurs de différentes affiliations théoriques. La deuxième traite de la configuration des politiques actuelles ainsi que des conditions de possibilité de l'expropriation du travail des enseignants. La troisième propose la notion de substitution technologique comme un lien entre les compétences et l'évaluation, en se concentrant sur le cas du secrétariat municipal de l'éducation de la municipalité de Rio de Janeiro. Finalement, la quatrième section se lance dans une analyse critique des discours des enseignants afin d'intensifier les sens en lice pour l'hégémonie.

Mots-clés: Politiques éducationnelles. Curriculum. Évaluation. Enseignement. Substitution technologique.

\section{Contexto e intertextos}

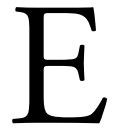

ste artigo foi produzido durante o período de consulta pública acerca da proposta da Base Nacional Comum Curricular (BNCC), apresentada com a pretensão de vir a nortear "o ensino, o aprendizado, a formaçáo docente e o material didático em nossa sociedade" (MEC, 2015, p. 2) ${ }^{1}$. Embora o documento abranja toda a escola básica, o foco aqui está posto no ensino fundamental, em função das pesquisas específicas em que se baseia ${ }^{2}$. Como os demais textos, é tecido em diálogo com outros, sendo a intertextualidade explícita uma característica da produção acadêmica.

Por outro lado, é oportuno o registro do fato de que, na tendência neotecnicista atual, parece estar se tornando corriqueira a ausência de referências bibliográficas em produçôes patrocinadas por corporaçóes, como ocorre no livro publicado por Lemov (2011), aqui destacado por ter sido distribuído gratuitamente aos aprovados em concurso para provimento no cargo de professor do quadro permanente de pessoal do município do Rio de Janeiro, no âmbito da Secretaria Municipal de Educação. Seu título é "Aula nota 10: 49 técnicas para ser um professor campeão de audiência" e seu patrocinador é a Fundação Lemann. Desprovido de quaisquer referências, o material se baseia apenas e tão somente em observaçóes de "boas práticas", no julgamento do autor.

Quanto aos intertextos fundamentais, refiro-me a Freitas (2014) e Macedo (2014), dois trabalhos com a mesma datação, ambos inclusive publicados no 
quarto trimestre, com abordagens diversas das questôes relativas ao trabalho e à formação docente, convergindo na análise do desenho de uma nova regulaçâao educacional. Trata-se, respectivamente, de "Os reformadores empresariais da educação e a disputa pelo controle do processo pedagógico na escola", em perspectiva histórica, e de "Base nacional curricular comum: novas formas de sociabilidade produzindo sentidos para educação", "articulando a teoria do discurso [pós-estruturalista], de Ernesto Laclau, com o conceito de redes de políticas, de Stephen Ball" (Macedo, 2014. p. 1530).

O primeiro aborda os "reformadores empresariais" na concepção de que:

A questáo da educação se resolve a partir de uma gestão eficaz das mesmas formas vigentes de organização pedagógica, associada a novas tecnologias educativas, responsabilização, meritocracia e privatização, motivando a consolidação de um neotecnicismo educacional (FREITAS, 2014, p. 1088).

A segunda nomeia os sujeitos e apresenta os links dos sites das instituiçôes financeiras e empresas: Itaú/Unibanco, Bradesco, Santander, Gerdau, Natura, Volkswagen, além das fundaçôes Victor Civita, Roberto Marinho e Lemann, bem como de organizaçóes como o Centro de Estudos e Pesquisas em Educação, Cultura e Ação Comunitária (CENPEC), Todos pela Educaçáo, Amigos da Escola, todas diretamente envolvidas na "expulsão das antigas formas de gestão da educação como bem público" (MACEDO, 2014, p. 1538).

$\mathrm{Na}$ conclusão sustentada por Macedo (2014, p. 1549):

Está em curso a construçáo de uma nova arquitetura de regulação e de que, nela, os sentidos hegemonizados para educação de qualidade estão relacionados à possibilidade de controle do que será ensinado e aprendido. Trata-se, portanto, de um discurso circular, no qual a medida da qualidade torna-se o seu esteio e a sua garantia. A evidência de qualidade se torna a própria qualidade que se está advogando. [...] Trata-se de um conjunto difuso de "inimigos da escola" de qualidade: gestão pública, desperdício de recursos, professores mal formados pelas universidades. Essas causas, genericamente apresentadas, são descritas a exaustão, lançando mão de um conjunto de dados estatísticos que não deixam dúvida sobre a necessidade de intervenção.

Nas palavras de Freitas (2014, p. 1093):

$\mathrm{Na}$ atual disputa pela escola, os reformadores empresariais da educação ampliaram a função da avaliação externa e deram a ela um papel central na indução da padronização como forma de permitir o fortalecimento do controle não só sobre a cultura escolar, mas sobre as outras categorias do processo pedagógico, pelas quais se irradiam os efeitos da avaliaçáo, definindo o dia a dia da escola. (destaque do autor) 
Do ponto de vista da regulação, Macedo (2014, p. 1533) destaca o fato de que "no Brasil, além dos parâmetros curriculares nacionais, em 1997 foram construídas matrizes de referência para a avaliação iniciada no começo da década”. Ou seja, não há como discutir as questóes relativas à BNCC fora da sua relação com a proposta de avaliação externa: quanto mais específicas forem as descriçóes, maior será a padronização e mais eficientes os instrumentos para aferir resultados. Assim, argumentos concentrados na "base" servem mais como cortina de fumaça ao movimento de assumi-la metonimicamente como sendo o todo, invocando estratégias como a de "democratização"3.

As consequências da avaliação externa nacional e censitária não se limitam à padronização, mas abrangem mudanças estruturais em todo o processo educacional, especialmente pelo recurso à meritocracia. Como afirma Freitas (2014, p. 1097), "a associação entre desempenho dos alunos e pagamento dos professores, seja como salário variável, seja como bônus anual, por exemplo, turbina definitivamente esta rede de relaçóes que se torna conflitiva e concorrencial”.

Em outras palavras, ambos os autores destacam as açóes dos parceiros privados na nova regulamentação, fundadas nas conexóes entre a proposta da BNCC e a avaliação. Os dois analisam o controle externo do trabalho pedagógico escolar, remetendo à compressão do espaço entre a concepção do que deve ser ensinado e a formulação de juízos de valor em relação aos resultados obtidos, traduzidos por padrôes de avaliação em índices específicos.

O nível de compressão do referido espaço permite que os objetivos sejam tomados como padrôes de avaliação e vice-versa, em uma indistinção que sustenta náo apenas discursos circulares mas o apagamento de relaçóes que historicamente têm constituído o trabalho pedagógico. Entre elas, cabe ressaltar a definição dos objetivos, conteúdos, métodos e avaliação, que deixa de caber aos professores, atingindo os pares (objetivos/avaliação e conteúdos/métodos) de que fala Freitas (2014, p. 1085) e, em última análise, a própria concepção do processo de trabalho (MARX, 1985, p. 202) como abrangendo: (1) finalidade; (2) matéria a ser trabalhada; e (3) instrumental/meios para tanto. Entre a BNCC que chega a determinar conteúdos/competências e a avaliação externa censitária, a uniformidade esvazia a complexidade do processo pedagógico, excluindo os professores concretos das decisóes relativas a ele $^{4}$.

\section{As políticas na configuração atual do trabalho pedagógico}

Os intertextos cotejados destacam dimensões importantes das políticas em curso. Entre elas, é importante reter duas proposições que constituem o foco deste artigo, tendo em vista as suas relaçóes com o contexto. A primeira corresponde às novas condiçóes de produção do ensino, sintetizadas por Freitas (2014, p. 1103) em termos de trabalho e formação docente: "bastando [...] professores 
improvisados treinados em seguir apostilas e obedecer". A segunda, apontada por Macedo (2014, p. 1551), implica aspecto central da cultura da avaliaçáo: "se não se pode [ainda] eliminar o professor desse processo, é preciso torná-lo cúmplice”.

Nesse ponto, vale esclarecer que a noção de "cumplicidade" pode ser questionada a partir de um quadro de referências histórico. Considerando que a autora opera com a concepção pós-estruturalista derridiana, cabem as aspas. Também parece relevante sublinhar que a razão para incluir matrizes de análise diversas é demonstrar que, mesmo por caminhos diferentes, as proposiçóes contestam a regulação ora posta.

Para desenvolver ambas as proposiçōes, também recorro a Saviani (2007) na abordagem da lógica da "pedagogia de resultados" (p. 1253) e retomo Barreto (2012, p. 993), com "a organização do ensino a partir de competências a serem submetidas a formas de avaliação unificada", para tentar dar conta da arquitetura como um todo e não incorrer em simplificaçóes representadas pela hipertrofia de um dos seus elementos.

Refiro-me especialmente às tecnologias da informação e da comunicação (TIC), às quais tem sido atribuída centralidade indevida, aqui tomadas como parte, e meio, da consolidação do deslocamento do professor como aquele que desempenha tarefas associadas à docência, no espaço comprimido apontado ao final da seção anterior. Postas como solução para todos os problemas, incluindo os que extrapolam o contexto escolar, as TIC têm sido referência fundamental nos discursos das políticas. São ícones da modernidade e, na maioria das vezes, postas como estratégia de "democratização". Sáo objetos visíveis e importantes para sustentar as inversôes caracterizadas por Chauí (1999): a substituiçāo da lógica da produção pela da circulação e da lógica do trabalho pela da comunicação. Acima de tudo, não ferem a lógica do mercado: quanto maior a presença da tecnologia, menor a necessidade do trabalho humano, bem como maior a subordinação real do trabalho ao capital e aos que se valem das tecnologias para ampliar as formas de controle do trabalho e dos seus produtos.

Nesse ponto, para dirimir possíveis dúvidas acerca da objetivação das TIC na educação, é oportuna a abordagem dos dois modos básicos da sua recontextualização (FAIRCLOUGH, 2006, p. 101), como "um fenômeno complexo, envolvendo, para além de uma simples colonização, um processo de apropriaçáo cujas características e resultados dependem das circunstâncias concretas dos diversos contextos". No limite, as TIC podem constituir recursos agregados ao processo de ensino-aprendizagem e, por outro lado, ser inscritas como estratégia de substituição tecnológica, implicando precarização e esvaziamento do trabalho docente.

Na história recente das políticas educacionais brasileiras, o ano de 2008 marca a distribuição de notebooks aos professores, primeiramente em regime de comodato e, em seguida, como doação. $\mathrm{O}$ discurso oficial evidenciava a aposta 
no acesso ao conhecimento disponível e às práticas educacionais socializadas, ao mesmo tempo em que trazia o reconhecimento tácito de que o salário percebido pelos docentes não favorecia a aquisição do hardware específicos.

A aposta nos objetos técnicos foi ampliada por programas que pretendiam estender aos alunos o acesso a notebooks barateados pela ausência de disco rígido, nos moldes do internacional One Laptop per Child (OLPC). Em todos esses programas, entretanto, não foi privilegiada, ou mesmo considerada, a questáo do acesso à internet, enfaticamente reivindicada por autores como Pretto (2002). Ademais, problemas como a ausência de recursos para a manutenção dos equipamentos permaneceram intocados, constituindo entrave significativo ao seu desenvolvimento ${ }^{6}$.

Do ponto de vista das políticas, é possível verificar que a aposta nas TIC ultrapassa o hardware e chega ao software (BARRETO, 2014) no enredo das ressignificaçóes do ensino que, por sua vez, integram as condiçóes de possibilidade das mudanças que não são apenas discursivas, mas envolvem todo o trabalho pedagógico no contexto escolar.

Para encaminhar uma aproximação das mudanças mencionadas, é aqui assumido o referencial teórico da análise crítica de discurso (ACD), de autoria de Fairclough (2001), focalizando a dimensão semântica das práticas discursivas: as escolhas lexicais, em geral, e os processos de ressignificação e de relexicalização, em particular. As ressignificaçóes compreendem a atribuiçâo de sentidos novos a palavras dicionarizadas, em deslocamentos que tendem a marcar sua inscriçẫo em matrizes outras. Já as relexicalizaçóes, ou novas lexicalizaçôes, correspondem à utilizaçấo de neologismos ou de termos já cunhados em outras áreas e para outros fins, para dar conta de sentidos que as palavras existentes não expressariam. A análise de ambos os processos é imperativa na caracterizaçáo dos movimentos de abandono, deslocamento e/ou apropriação de palavras em diferentes contextos e matrizes conceituais, assim como de cunhagem de outras para dar conta de novos aspectos da "realidade".

Em se tratando dos processos de ensinar e aprender, há deslocamentos básicos a serem considerados. Um deles é a frequência cada vez menor com que os primeiros são referidos, enquanto os últimos se tornam mais e mais recorrentes. Na maioria das vezes, o substantivo "ensino" vem acompanhado de complementos como nível, modalidade e conteúdo envolvido. Enquanto isso, a aprendizagem, que até parece prescindir do ensino (autoaprendizagem), tende a não ser objetivada como processo interno, mas como produto (aprendizado) a ser mensurado.

Entre as condições de possibilidade na produção desses deslocamentos do ensino como trabalho docente, parece relevante retomar os já citados elementos que historicamente o constituem: sujeitos (professores e alunos), objetivos, conteúdos/métodos e avaliação. Neles, a primeira quebra significativa é promovida entre conteúdo e método que, em face de uma leitura liberal da Escola Nova, resultou na secundarização do primeiro elemento, deslocando a ênfase para os 
métodos e técnicas de ensino. A segunda, levada ao limite pelo tecnicismo dos anos 1970, reduz o ensino à formulação dos objetivos educacionais como comportamentos observáveis, de preferência acompanhados de condiçóes e critérios. Uma vez definidos, não deixam espaço para o não previsto, já que são balizados pelo exigido nas provas. Quanto à avaliação, passou a ser necessariamente externa, para classificaçôes e ranqueamentos que visam à responsabilização e meritocracia (RAVITCH, 2010), mais do que à formulação de juízos de valor acerca do trabalho desenvolvido. Finalmente, o neotecnicismo em curso bane as consideraçóes acerca dos sujeitos, articulando o reducionismo tecnicista à sofisticação tecnológica.

O já citado movimento que vai do hardware ao software é sustentado por uma relexicalização a ser sublinhada. Não se trata mais de materiais de ensino, mas de "objetos de aprendizagem" (OA), em tradução literal da língua inglesa, diferentemente de ensino a distância, por exemplo. Muda o eixo, na medida em que a sua definição destaca, invariavelmente, a condição de modelos supostamente aplicáveis aos mais diferentes contextos, com a vantagem adicional da reutilização sem limites. Os OA são uma espécie de "tradução" de competências, sejam elas postas como parâmetros, bases ou descritores para o alcance dos padróes desejáveis. Em outras palavras, o caminho aberto pelo uso intensivo das TIC em programas de ensino/educação a distância $(\mathrm{EAD})$ está agora pavimentado para quaisquer situaçóes de ensino.

Uma demonstração da ausência de espaço para o trabalho docente tem sido a configuração dos discursos das políticas específicas, estruturadas a partir de diagnósticos dos problemas a serem enfrentados e da identificação de soluçóes centradas nas TIC. É o caso, por exemplo, do documento "Pátria Educadora: a qualificação do ensino básico como obra de construção nacional" (BRASIL, 2015), que culmina com a determinação de "tecnologias e técnicas" para viabilizar os avanços pretendidos: "vídeos e softwares" (p. 29).

Por outro lado, o documento é coerente ao afirmar que náo se trata de "substituir o professorado" (p. 29). Náo se trata mesmo de substituir os professores pelas TIC, mas o trabalho docente pelas TIC, com todas as consequências políticas e práticas, operando mudanças profundas a ponto de reconfigurar todo o processo, desde a formação ao exercício profissional.

\section{Substituição tecnológica: elo entre competências e avaliação}

Em primeiro lugar, é importante reconhecer que essa noção pode ser alvo de objeçóes relacionadas à sua inscrição teórica e ideológica. "Substituição tecnológica" pode sugerir uma perspectiva simplista que a coloca no mesmo plano da substituição de quadros de giz pelas chamadas lousas digitais, de canetas, cadernos e livros por computadores etc., como se sua diferença 
residisse apenas no fato de substituir açóes de professores por programas didáticos cada vez mais sofisticados.

É possível afirmar que os OA materializam a aposta na substituição tecnológica como solução para os problemas educacionais, deslocados para uma dimensão técnica renovada. São armazenados em espaços virtuais sugestivamente chamados de "bancos", em níveis federal, estadual e municipal: o banco internacional constante do portal do Ministério da Educação (MEC); programas como Conexão Professor, da Secretaria de Estado de Educação, do Rio de Janeiro; e a Educopédia, da Secretaria Municipal de Educação do Rio de Janeiro.

De um lado, se os OA podem ser postos como ícones da substituiçáo tecnológica, de outro, em si não dão conta dos vários desdobramentos e dimensôes das políticas em curso ${ }^{7}$. Assim, reconhecendo a fragilidade teórica das análises limitadas a generalizaçôes, bem como a miríade de programas e projetos formulados e em processo de formulaçáo no contexto nacional, este artigo assume um caso exemplar: o conjunto das políticas desenvolvidas pela Secretaria Municipal de Educação do Rio de Janeiro (SME-RJ), a partir de 2009, desde a administração Cláudia Costin, cujo convite para o cargo de Secretária de Educação Básica do MEC, em 2012, "motivou uma das maiores mobilizaçóes recentes de professores universitários, dirigentes sindicais, representantes de entidades acadêmicas e de docentes da educação básica” (EVANGELISTA; LEHER, 2012, p. 3$)^{8}$.

A focalização da SME-RJ se deve ao fato de ser essa a maior rede pública de ensino fundamental do país e à sua inflexão no sentido de "assegurar a excelência na Educação Pública no Ensino Fundamental e na Educaçáo Infantil”, traduzida em um conjunto de medidas, dentre as quais são aqui destacadas:

1. a criação da plataforma Educopédia, banco próprio de objetos de aprendizagem, em 2010, cobrindo todas as aulas previstas para o ano letivo e tendo como "educoparceiros", entre outros, a Fundação Roberto Marinho, a Microsoft e a Intel;

2. o Programa Ginásio Experimental Carioca (GEC), sustentado pela proposta de utilizaçáo intensiva da plataforma Educopédia e pela interposiçáo da figura do "professor polivalente", criado pelo Decreto no 32.672, de 18 de agosto de 2010 (RIO DE JANEIRO, 2010a);

3. o Projeto $6^{\circ}$ Ano Experimental, a ser desenvolvido por "Professor II com graduação", "capacitado" nos termos do Parecer no 30, de 30 de dezembro de 2010; e

4. a criação da Escola de Formação do Professor Carioca - Paulo Freire, como lócus de capacitação docente, conforme o Decreto no 35.602, de 09 de maio de 2012 (RIO DE JANEIRO, 2012). 
Em se tratando da Educopédia, é importante esclarecer que não se trata de simplesmente rejeitar o armazenamento de sequências de ensino ("aprendizagem"), mas a sua condição de modelos supostamente aplicáveis a quaisquer situaçôes. O cerne do problema está na sua inscrição como ícones da modernização e do desenvolvimento, esvaziando o trabalho docente pelo controle, sem precedentes, exercido através de materiais acompanhados de variaçóes em torno de instruçóes de uso.

Também é relevante sublinhar que a suposta centralidade das TIC é posta em xeque nos contextos em que o acesso a elas é mais difícil. O que é redimensionado são as tecnologias, sendo defendido o uso de materiais impressos, produzidos em nível central e distribuídos aos professores. No caso da SME-RJ, a utilização também intensiva dos Cadernos Pedagógicos atesta o reconhecimento de que o acesso à internet nas escolas é muito difícil, quando não inviável. Mesmo sem entrar aqui no mérito econômico da publicação desses materiais, vale pontuar que eles sim constituem a conhecida e simples substituição tecnológica: a do meio digital pelo retorno ao impresso.

Em relação ao conteúdo dos Cadernos Pedagógicos, duas observaçóes são cabíveis. A primeira é a de que eles são produzidos em função dos "descritores" que sustentam os objetivos e a avaliação no contexto específico. A segunda é a de que eles veiculam perspectiva estreita dos conteúdos a serem aprendidos/avaliados, além de serem eivados de erros crassos?

Cabe ressaltar que o modelo de substituição tecnológica está presente há décadas no discurso dos organismos internacionais. Desde Labarca (1995), é possível detectar a ressignificação da própria tecnologia, como combinação de recursos materiais e humanos. Nesses termos, o professor é sempre a "tecnologia" mais cara: exige um longo processo de formação, atende a um número limitado de alunos, tem direitos trabalhistas, tempo para preparar aulas, fazer avaliaçóes etc. Seguindo essa lógica, o autor afirma que, com o uso intensivo do recurso humano, a educação dificilmente poderá melhorar a sua produtividade. Propóe o uso intensivo de tecnologias para permitir que os professores deixem de ser "os principais depositários do conhecimento", passando à condição de "animadores de grupos de trabalho" (LABARCA, 1995, p. 175). Em outras palavras, é mais rentável o investimento inicial maciço em materiais, mais ou menos sofisticados, desde que possam ser reproduzidos e reutilizados um sem-número de vezes. Com as TIC, é possível ampliar o acesso à educação e, ao mesmo tempo, reduzir o seu custo.

No que tange aos desdobramentos da substituição tecnológica na SME-RJ, o Ginásio Experimental Carioca e o $6^{\circ}$ Ano Experimental são cruciais. O primeiro, compreendendo do $7^{\circ}$ ao $9^{\circ}$ anos, envolve a reorganizaçáo dos horários com aulas mais longas em turno único, bem como atividades complementares que incluem disciplinas eletivas, estudo dirigido, tutoria, Protagonismo Juvenil e Projeto de Vida (COSTA, 2015). Sua concepçâo faz referência ao "resgate de uma dívida 
social", à utilização das TIC e à ação de "professores polivalentes - um para Matemática e Ciências (Exatas), outro para Português, História e Geografia (Humanidades) e professores especialistas que trabalharão Educação Física, Artes e Inglês".

Extintos formalmente nos termos do Decreto no 38.954, de 17 de julho de 2014 (RIO DE JANEIRO, 2014), os GECs apenas deixaram de ser experimentais. Curiosamente, a ambiguidade detectada no referido documento só é esclarecida no Parecer no 30, de 30 de dezembro de 2010 (RIO DE JANEIRO, 2010b), que trata do $6^{\circ}$ Ano Experimental: "A partir do ano letivo de 2011, as escolas da Rede Pública Municipal de Ensino do Rio de Janeiro que atendem o segundo segmento do Ensino Fundamental serão denominadas Ginásios Cariocas", enfatizando ainda que elas "terão assegurados como principais suportes a utilização de material pedagógico estruturado e o uso da Educopédia".

Já a formulação acerca do $6^{\circ}$ Ano Experimental não contempla argumentos que extrapolem o número de professores com os quais o aluno passa a interagir, em contraposição ao professor único presente nos anos iniciais. Entre as justificativas apresentadas, a mais recorrente tem sido a da suposta falta de maturidade na passagem da infância para a adolescência e do primeiro para o segundo segmento do ensino fundamental (BRITO, 2016). É o professor generalista. Também é sublinhado que "esses alunos receberão o mesmo material pedagógico destinado às demais turmas de $6^{\circ}$ ano e terão acesso à Educopédia”.

Por "material pedagógico estruturado", entenda-se material pronto. Quanto ao acesso e ao uso da Educopédia, permanece a sua mistificação. Por um lado, é atribuído a ela um nível de excelência que náo resistiria a diferentes análises. Por outro, são ignoradas as condiçôes objetivas e proibitivas verificadas nas escolas.

Completando o quadro dos desdobramentos da substituição tecnológica, está a criação da Escola de Formação do Professor Carioca - Paulo Freire, sem qualquer relação com as instituiçóes locais de formação de professores. A proposta não dialoga com as várias universidades localizadas no Rio de Janeiro e se refere à preparação dos professores ingressantes e em exercício na rede municipal, embora a ênfase esteja posta nos primeiros, até por força dos editais mais recentes, que preveem curso de curta duração intensivo e prova de aula mais curta, nos moldes das propostas de microensino com que o tecnicismo dos anos 1970 operava no treinamento de habilidades específicas.

Entrevistas com professores que passaram pela experiência do curso dáo conta de que a dita formação básica está concentrada: na fixação dos "descritores" das competências e habilidades que sustentam a avaliação na rede; e no treinamento para o uso da Educopédia, mesmo sem haver garantia de infraestrutura mínima nas escolas de destino, hipótese em que a centralidade é atribuída aos Cadernos Pedagógicos.

Por outro lado, é relevante registrar a fala de uma das professoras participantes do curso: "Já sou da rede e gostaria de acrescentar que já fui professora 
da rede particular e não quero mais voltar. $\mathrm{O}$ município é ótimo. Nos dá tudo mastigado. Entro na minha sala e já sei o que vou dar naquele dia, sem dor de cabeça. Está tudo pronto".

A partir desse discurso, é possível dimensionar os sentidos do lugar de professor em disputa por hegemonia. Objetivando as relaçóes entre as TIC e o trabalho docente, são retomadas na seção final as proposiçôes retidas de Freitas (2014, p. 1113) - "professores improvisados treinados em seguir apostilas e obedecer" - e Macedo (2014, p. 1551) — "se não se pode [ainda] eliminar o professor desse processo, é preciso torná-lo cúmplice". Em outras palavras, o treinamento dos improvisados para a obediência passa pela produçấo de uma cumplicidade singular.

\section{Professores: de "especialistas" a polivalentes e generalistas}

Os deslocamentos consignados no título acima implicam uma cadeia de ressignificações e relexicalizações, a começar pela adjetivação: da suposta valorizaçáo da condição de graduados em uma determinada disciplina (especialistas) para a de atuantes no GEC (polivalentes) e no $6^{\circ}$ Ano Experimental (generalistas).

No sentido da produção da cumplicidade, há vantagens oferecidas para a aceitação das novas condiçóes de "trabalho". No caso do GEC, o professor em regime de tempo parcial pode ter o salário dobrado e acrescido de $15 \%$ de bonificação, desde que tenha presença integral. Nas palavras de uma professora:

[...] todo mundo achou maravilhoso o fato da escola virar um turno único, aliás, turno único a gente já era, viramos integral, e ganhar mais, ganhar o extra, a gente viu o bônus... não analisou o ônus e você tem que botar a mão na massa no turno único. O trabalho é extra, porque você vai ensinar uma coisa que você tem que aprender antes, não tem como...

Em se tratando do $6^{\circ}$ Ano Experimental, a única vantagem concreta é a possibilidade de assumir uma posição de "Professor I", cujo status parece em princípio atraente aos professores II, até então restritos ao primeiro segmento. Além disso, aceitar a condição de generalista pode significar trabalhar em escolas mais interessantes, especialmente pela proximidade em relaçáo ao domicílio. Afirma uma generalista:

Acho ruim porque os meninos acabam sendo prejudicados. Eu não domino a disciplina Matemática como um professor que se formou em Matemática. Me sinto meio culpada, mas tive que aceitar lecionar nessa turma senão ficaria muito longe de casa e tenho um filho pequeno. 
É possível afirmar que o deslocamento maior acaba envolvendo vantagem menor. Talvez essa seja uma razão para a espécie de "arrependimento" e de sentimento de culpa manifestados pelos professores do $6^{\circ}$ Ano Experimental, embora a perspectiva crítica esteja marcada nos seus discursos:

Só a Prefeitura ganha com esse projeto. Os alunos terminam o ano letivo defasados e os professores exaustos.

[...] me vejo obrigada a dar aula de assuntos que náo tenho formação para lecionar. Dessa forma, por mais que eu me esforce, a educação dos meus alunos se torna aligeirada. E eu por vezes me culpo por isso. É nitidamente uma questáo de se gastar menos com educação. Faço o trabalho de cinco professores e, como é para pobre, pode. (destaque meu)

Já o gestor do GEC pesquisado produz discurso mais afinado com as propostas da SME e chega a dizer que:

Eu achei muito bom. [...] para mim foi ótimo! Você ser de uma área, ser catedrático (sic)... aquela cadeira ser sua, e de repente você passa a ministrar aula de uma outra coisa que você náo conhece bem, primeiro que você tem que estudar, e você vai transmitir aquilo não sendo o detentor daquele conhecimento, então acho que você transmite com mais facilidade. Com mais dúvidas, você pesquisa mais e pesquisa melhor, e acho que isso tudo faz com que o aluno acompanhe o professor e vai aprendendo com o professor. E o professor aprendendo com o aluno. (destaques meus)

Nessa e em outras falas referentes ao GEC, parece haver a ressignificação de expressóes como "zona de conforto" e até de "objetividade", concebida como limitação estreita ao que será avaliado. Ao mesmo tempo, ocorrem novas lexicalizaçóes dos elementos apagados do processo, como é o caso do planejamento: "Se eu tenho que dar determinada coisa, eu vou lá meia hora antes, pego os vídeos e monto uma aula" (destaque meu).

Por outro lado, as situaçóes decorrentes do esvaziamento do trabalho docente produzem efeitos que atingem até mesmo a identidade dos profissionais, como em: "meus alunos sempre tiram nota melhor em Geografia do que em História. E eu era de História" (destaque meu). É o caso de:

Em alguns casos, o sujeito chega a negar qualquer contribuição sua.

Quando você me perguntou se eu uso a Educopédia, eu não uso, mas Z faz os meus testes, não sou eu que faço os testes, eu não preparo teste. E algumas vezes ele usa sim. Eu não contribuo com nada, mas eu utilizo o que ele prepara, não sei se ele tem tirado da Educopédia, mas alguma vez ele já fez isso. (destaque meu) 
Cabe pontuar que os polivalentes não são obrigados a lidar com conteúdos que extrapolam, em muito, a "área" da sua formação, exceto no caso de Português, História e Geografia. Também podem ter o apoio de "especialistas" na escola, além de contar com alguma cumplicidade dos alunos:

[...] quando surge alguma dúvida eu digo que vou perguntar ou para X ou Y. É muito natural isso (risos). Eles [os alunos] náo se incomodam. Quando surge alguma dúvida, eles perguntam: $\mathrm{X}$ não está aí? Eu também tenho dúvidas, não tenho aquela didática, aquele raciocínio rápido, não tenho. Mas aí na hora consigo tirar as dúvidas e passar para os alunos.

A representação do professor como aquele que "sabe" o conteúdo a ser ensinado fica ainda mais comprometida quando se trata dos generalistas, majoritariamente graduados em Pedagogia. Como afirma uma delas:

O tempo inteiro preciso recorrer às tecnologias. [...] Elas funcionam como uma bengala, já que não domino as disciplinas. [...] Utilizo a Educopédia mesmo achando o material de péssima qualidade. É onde eu me apoio pra náo acabar falando besteira.

A metáfora da "bengala" é recorrente, tendo como variação agravante a da "muleta". O constrangimento com que professores se referem às suas condiçóes de trabalho pode ser verificado na modalização indevida de termos como "domínio": "uso as apostilas também e vídeos para disciplinas que eu domino menos" (destaque meu). $\mathrm{O}$ nível de constrangimento se torna indisfarçável quando o tema é a avaliação:

Eu até dou algumas avaliaçóes elaboradas por mim, mas não servem de nada. No final das contas a que conta é a avaliação que já vem pronta. Mesmo que eu tenha concluído com a minha avaliação que o aluno está mal em determinada disciplina, se ele vai bem na prova externa é o que conta. (destaques meus)

Confesso que não tenho muito tempo de fazer as minhas próprias avaliaçôes e acabo preparando meus meninos para a avaliação externa [...] principalmente porque além da escola os pais cobram bons resultados nela. (destaques meus)

Tanto no que diz respeito aos polivalentes quanto aos generalistas, merecem registro as táticas utilizadas para contornar a ausência de conectividade nas escolas: o recurso sistemático a pen drives. Havia uma gaveta deles no GEC, fazendo com que os professores chegassem mais cedo para efetuar a busca, e uma generalista afirma: "uso Educopédia, mas salvo em um pen drive porque nem sempre a internet funciona”. 
O conjunto das estratégias da SME e das táticas dos profissionais configuram os desdobramentos atuais da recontextualização das TIC como substituição tecnológica. A triangulação das competências de base, TIC e avaliação externa permite a intensificação do uso da força de trabalho e pode sugerir uma suposta revoluçáo tecnológica: cada vez mais alunos atendidos por menos professores e, até, cada vez mais demonstraçôes da eficiência dos meios para os fins estabelecidos. Com tantos materiais disponíveis, cabe aos professores controlar o tempo de contato dos alunos com eles. Com o deslocamento do foco do ensino para os materiais, geralmente vistos como "autoinstrucionais", são esvaziados os vínculos lógicos entre as tecnologias a serem utilizadas no ensino e a formaçáo do professor. Bastam cursos rápidos de treinamento. Bastam aulas "montadas" alguns minutos antes. Vale "tudo mastigado".

Retomando as formulações de Freitas (2014) e Macedo (2014), registradas na primeira seção, bem como as políticas assumidas pela SME, é possível verificar que os discursos dos professores podem se apresentar mais ou menos sintonizados com as tentativas de controle de todo o processo pedagógico escolar. Essa nova arquitetura de regulação, concretizada no ensino fundamental, produz a compressão do espaço entre a base curricular e a avaliação, a ponto de prescindir do domínio dos conteúdos e admitir diferentes formas de improvisação, desde que obedecidas as condiçôes postas para a consecução dos resultados esperados.

A incorporação das TIC como estratégia de substituição tecnológica preenche o espaço que corresponderia ao processo de trabalho docente, permitindo um nível de controle até então insuspeitado. Contudo, é preciso sublinhar que não trata apenas de tecnologias em outro patamar e grau de sofisticação, mas de instância de tradução de uma BNCC que inclui listagens de conteúdos/competências apontando para avaliações unificadas centradas nos produtos, em um enredo que mantém a mistificação das TIC, com o reforço das parcerias público-privadas patrocinando a encenação.

Em síntese, entre a BNCC e a avaliação externa, o espaço tende a ser preenchido pelos "objetos de aprendizagem".

\section{Notas}

1. Texto assinado pelo então Ministro Renato Janine Ribeiro, ora reafirmado por campanha publicitária (https://www.youtube.com/channel/UCn9sSXxb1Pd3v6bszZRssJA) como sendo "o que deve ser ensinado na escola básica". A sigla está reduzida a BNC no sítio do Ministério da Educação, embora a referida campanha repita, estranhamente, na mesma frase, a designação completa: Base Nacional Comum Curricular.

2. Baseado em pesquisas financiadas pelo Conselho Nacional de Desenvolvimento Científico e Tecnológico (CNPq) e pela Fundação de Apoio à Pesquisa do Estado do Rio de Janeiro (FAPERJ). 
3. As aspas pretendem demarcar as ressignificaçôes dos conceitos envolvidos, sempre em disputa, comumente invocados para legitimar propostas políticas. Em se tratando da democracia, Coutinho (2008) sublinha que, "sobretudo a partir dos anos 1930, o liberalismo assumiu a democracia e passou a defendê-la, ainda que não sem antes minimizá-la, empobrecendo suas determinaçôes, concebendo-a de modo claramente redutivo. Assim, pelo menos nominalmente, hoje todos são democratas”.

4. Restam estratégias de gestão em níveis centrais para fazer com que alunos considerados fracos e potencialmente comprometedores de resultados positivos sejam retirados da população, com o seu deslocamento para programas especiais, fora do censo.

5. Não são discutidas neste texto as questôes relativas aos meandros da aquisição dos equipamentos, ou mesmo as contestaçôes da sua qualidade, mas cabe destacar que o critério técnico parece ter sido o da maior portabilidade, razão pela qual a proposta para o ensino médio esteve centrada em tablets.

6. O Programa Um Computador por Aluno (PROUCA) é abordado em Barreto (2014), notadamente no que diz respeito a Rio das Flores, Rio de Janeiro.

7. A noção de substituição tecnológica permite superar simplificaçôes correntes, como a representada pela oposição de ensino presencial e a distância, na perspectiva de simples "modalidades", definidas em função do seu modus operandi. A perspectiva é a da distinção entre a substituição tecnológica total (EAD) e a parcial (ensino presencial), em que há um professor em cena, mas relegado a um segundo plano, operando com aspectos periféricos como o controle do tempo de contato dos alunos com os OA.

8. A administradora em questão tornou-se diretora global de educação do Banco Mundial e tem se pronunciado contra a lei do piso nacional do magistério, que inclui a atribuiçáo de $30 \%$ da jornada de trabalho ao planejamento. O argumento é o de que a medida dificultará a melhoria dos salários, por exigir a contrataçấo de um terço a mais de professores. Insiste que "a métrica tem que ser o aprendizado do aluno. Este é o foco" (Cf. http://www1.folha.uol. com.br/mercado/2015/11/1705186-brasil-armou-bomba-para-contas-publicas-na-educacao-diz-diretora-do-banco-mundial.shtml). Parte de pressuposto de que o planejamento não tem relaçáo com o foco, sendo, portanto, desnecessário.

9. Apenas para citar dois exemplos, em 2013, o Caderno de Matemática designou Belém como capital de Pernambuco e, em 2015-2016, o de Ciências propôs a identificação dos tipos de alimentos contidos nas imagens, sendo uma das opçôes "cereais e pãos" (sic).

\section{Referências}

BALL, S.J. Educação global S.A.: novas redes políticas e o imaginário neoliberal. Tradução de Janete Bridon. Ponta Grossa: UEPG, 2014.

BARRETO, R.G. A recontextualização das tecnologias da informação e da comunicação na formação e no trabalho docente. Educação \& Sociedade, v. 33, n. 121, p. 985-1002, dez. 2012.

et Alii, 2014.

Tecnologias e trabalho docente: entre políticas e práticas. Petrópolis: De Petrus 
BRASIL. Pátria Educadora: a qualificação do ensino básico como obra de construção nacional. Brasília: Presidência da República, 2015. Disponível em: https://avaliacaoeducacional. files.wordpress.com/2015/04/qualificacao-do-ensino-basico-documento-para-discussao. pdf. Acesso em: 12 jun. 2015.

BRITO, K.L. Os desdobramentos da substituição tecnológica no Município do Rio de Janeiro. 140f. Dissertação (Mestrado) - Faculdade de Educação. Universidade do Estado do Rio de Janeiro, Rio de Janeiro, 2016.

CHAUÍ, M. Ideologia neoliberal e universidade. In: OLIVEIRA, F.; PAOLI, M. C. (Org.) Os sentidos da democracia: políticas do dissenso e hegemonia global. Petrópolis: Vozes, 1999. p. 27-51.

COSTA, K.B.B.M. O trabalho docente e as tecnologias no Programa Ginásio Experimental Carioca. 127f. Dissertação (Mestrado) - Faculdade de Educação. Universidade do Estado do Rio de Janeiro, Rio de Janeiro, 2015.

COUTINHO, C.N. Democracia: um conceito em disputa. Disponível em: http://laurocampos. org.br/2008/12/democracia-um-conceito-em-disputal. Acesso em: 28 jun. 2015.

EVANGELISTA, O.; LEHER, R. Todos pela Educação e o episódio Costin no MEC: a pedagogia do capital em ação na política educacional brasileira. Trabalho Necessário, v. 10, n. 15, p. 1-29, 2012.

FAIRCLOUGH, N. Language and globalization. London: Routledge, 2006. . Discurso e mudança social. Brasília: Editora da UNB, 2001.

FREITAS, L.C. Os reformadores empresariais da educação e a disputa pelo controle do processo pedagógico na escola. Educação \& Sociedade, Campinas, v. 35, n. 129, p. 1085-1114, out.-dez., 2014.

LABARCA, G. Cuánto se puede gastar en educación? Revista de la CEPAL, n. 56, p. 163-178, ago.1995.

LEMOV, D. Aula nota 10: 49 técnicas para ser um professor campeão de audiência. São Paulo: Da Boa Prosa, Fundação Lemann, 2011.

MACEDO, E. Base Nacional Curricular Comum: novas formas de sociabilidade produzindo sentidos para educação. Revista e-Curriculum, São Paulo, v. 12, n. 3, p. 1530-1555, out./dez., 2014.

MARX, K. O capital. Livro 1, Volume 1. 10. ed. São Paulo: Difel, 1985.

MINISTÉRIO DA EDUCAÇÃO - MEC. Base Nacional Comum Curricular. Brasília: MEC/SEB, 2015.

PRETTO, N.D.L. Formação de professores exige rede! Revista Brasileira de Educação, n. 20, p. 121-131, maio/ago., 2002.

RAVITCH, D. The death and life of the Great American School System: how testing and choice are undermining education. New York: Basic Books, 2010. 
RIO DE JANEIRO. Decreto no 32672, de 18 de agosto de 2010a. Cria o Programa Ginásio Carioca no âmbito da Secretaria Municipal de Educação e dá outras providências. Disponível em <http://smaonline.rio.rj.gov.br/legis consulta/34691Dec\%2032672 2010.pdf>

Conselho Municipal de Educação. Parecer no 30, de 30 de novembro de 2010 b. Aprova a implantaçáo do Projeto $6^{\circ}$ Ano Experimental na Rede Pública do Sistema Municipal de Ensino do Rio de Janeiro. Diário Oficial do Município do Rio de Janeiro, Ano XXIV, n. 186, p. 10. Disponível em: <http://doweb.rio.rj.gov.br/ler pdf.php?edi id=1079\&page=10>

. Decreto $\mathrm{n}^{\circ} 35602$, de 09 de maio de 2012. Altera a estrutura organizacional da Secretaria Municipal de Educação - SME. Disponível em < $\underline{\text { http://doweb.rio.rj.gov.br/ }}$ visualizar_pdf.php?edi_id=1718\&page=3>

. Decreto no 38.954, de 17 de julho de 2014. Dispóe sobre o funcionamento das unidades escolares assistidas pelos programas Ginásio Experimental Carioca e Ginásio Experimental Olímpico e Paralímpico e dá outras providências. Disponível em: $<\underline{\text { http:// }}$ leismunicipa.is/bsjmt>

SAVIANI, D. O Plano de Desenvolvimento da Educação: análise do Projeto do MEC. Educação \& Sociedade, Campinas, v. 28, n. 100 - Especial, p. 1231-1255, out. 2007.

Recebido em 16 de fevereiro de 2016.

Aprovado em 15 de agosto de 2016. 